\title{
Utilidad clínica de la medición de la hormona antimülleriana en niños
}

\author{
Clinical utility of anti-mullerian \\ hormone measurement in children
}

\section{Juan D. Lasprilla-Tovar MD', Carolina Henao-Ochoa MD', Juan M. Alfaro-Velásquez MD³, Germán Campuzano-Maya MD ${ }^{4}$}

Resumen: la hormona antimülleriana, inicialmente denominada sustancia inhibitoria mülleriana, es una glicoproteína homodimérica de 12,5 kDa, que pertenece a la familia del factor de crecimiento transformante beta (TGF- 6 ) y desempeña un papel crucial en la diferenciación sexual masculina al favorecer la regresión de los conductos de Müller. Dado que su producción en el varón es principalmente por las células de Sertoli inmaduras, en las últimas décadas ha crecido su utilidad más allá de la evaluación de la función ovárica y tratamientos de fertilidad en las mujeres, lo que ha permitido evaluar en el varón la función testicular y los estados de hipogonadismo, trastornos de la diferenciación sexual, pubertad patológica, criptorquidia, entre otras condiciones clínicas revisadas en este manuscrito. Además, esta revisión describe el rol fisiológico de la hormona antimülleriana en los testículos prepuberales y las pruebas de laboratorio disponibles para su medición.

Palabras clave: hormona antimülleriana, masculino, células de Sertoli, diferenciación sexual, trastornos testiculares del desarrollo sexual 46, XX, hipogonadismo, criptorquidismo, síndrome de Klinefelter.

Lasprilla-Tovar JD, Henao-Ochoa C, Alfaro-Velásquez JM, Campuzano-Maya G. Utilidad clínica de la medición de la hormona antimülleriana en niños. Medicina \& Laboratorio 2017; 23: 311-330.

${ }^{1}$ Médico, especialista en Pediatria, residente de Endocrinología Pediátrica, Universidad de Antioquia. Medellín, Colombia Correo electrónico: juandavidba@gmail.com

${ }^{2}$ Médica, especialista en Pediatría, residente de Endocrinología Pediátrica, Universidad de Antioquia. Medellín, Colombia. ${ }^{3}$ Médico, especialista en Pediatría y Endocrinología Pediátrica. Director Departamento de Endocrinología Pediátrica, Universidad de Antioquia. Medellín, Colombia.

${ }^{4}$ Médico, especialista en Hematología y Patología Clínica. Docente Ad Honorem, Facultad de Medicina, Universidad de Antioquia. Coordinador Grupo de Investigación en Patología Clínica. Médico Director, Laboratorio Clínico Hematológico. Medellin, Colombia.

Conflicto de intereses: Ios autores declaran que no tienen conflictos de intereses Medicina \& Laboratorio 2017; 23: 311-330

Módulo 1 (La Clínica y el Laboratorio), número 123. Editora Médica Colombiana S.A. 2017C Recibido el 30 de julio de 2017; aceptado el 30 de agosto de 2017 
a hormona antimülleriana, descrita inicialmente en 1947 por el doctor Alfred Jost, fue propuesta como un factor testicular que causaba la regresión de los conductos müllerianos y fue denominada, inicialmente, como la sustancia inhibitoria mülleriana. Esta hormona es una glicoproteína homodimérica de $12,5 \mathrm{kDa}$, que pertenece a la familia del factor de crecimiento transformante beta (TGF- $\beta$ ), cuyo gen se encuentra en el cromosoma 19 p13.3 y está compuesto por cinco exones. Es creada como una preproteína de longitud completa que sufre un proceso de proteólisis, el cual da lugar a dos productos homodímericos, los N-terminales, conocidos como la prorregión, y los C-terminales, correspondientes a la región madura, los cuales se asocian para formar un complejo no covalente biológicamente activo y con capacidad para unirse a su receptor (véase figura 1) [1-6].

El receptor tipo II específico para la hormona antimülleriana (AMH-RII) es una proteína transmembrana heteromérica con actividad serina treonina quinasa, que se expresa a nivel de la membrana celular de los conductos müllerianos, en las células de Leydig y las células de Sertoli a nivel testicular, al igual que en las células de la granulosa en el ovario. La disociación de la prorregión del complejo no covalente de la hormona antimülleriana ocurre en el momento en que este se une a su receptor y es requerida para estimular la señalización intracelular mediada por la fosforilización de Smad, lo que genera y mantiene la actividad biológica de la hormona (véase figura 1).[1,7-11].

La hormona antimülleriana es producida en el hombre principalmente por las células de Sertoli inmaduras, en los que cobra suma importancia durante la diferenciación sexual en el feto al inducir la regresión de los conductos de Müller, lo que favorece el desarrollo de los genitales masculinos internos $[9,12]$. Dado que la secreción de la hormona antimülleriana al torrente sanguíneo en el hombre se realiza exclusivamente por las células de Sertoli, esta hormona es uno de los marcadores de mayor utilidad para el estudio de la función testicular en los varones prepuberales, en los que la testosterona basal y el conteo de espermatozoides no son adecuados para este fin, dado que las células gonadotropas y las células testiculares de Leydig se encuentran inactivas y el semen no se produce [13].

El objetivo de este segundo manuscrito sobre la hormona antimülleriana es complementar el publicado en el anterior número de MEDICINA \& LABORATORIO, donde se analizaron aspectos relevantes del desarrollo del sistema reproductivo y la diferenciación sexual femenina, al igual que las principales características de la hormona antimülleriana como su estructura, producción y función en la mujer para entender la utilidad clínica de su medición para determinar la función y reserva ovárica en los casos de fecundación in vitro, envejecimiento ovárico (menopausia), tumores de células de la granulosa, síndrome de ovario poliquístico e insuficiencia ovárica por radioterapia, quimioterapia o cirugía ovárica [14].

En el presente manuscrito se analizará la fisiología de la hormona antimülleriana en los testículos prepuberales y su aplicación clínica para la evaluación de los trastornos de la diferenciación sexual en el hombre y en el estudio del hipogonadismo central, el síndrome de Klinefelter, la criptorquidia y la anorquia, la pubertad precoz y atrasada, la toxicidad gonadal inducida por quimio o radioterapia, el macroorquidismo y los tumores de las células de Sertoli, junto con la descripción de las principales técnicas para su medición. 


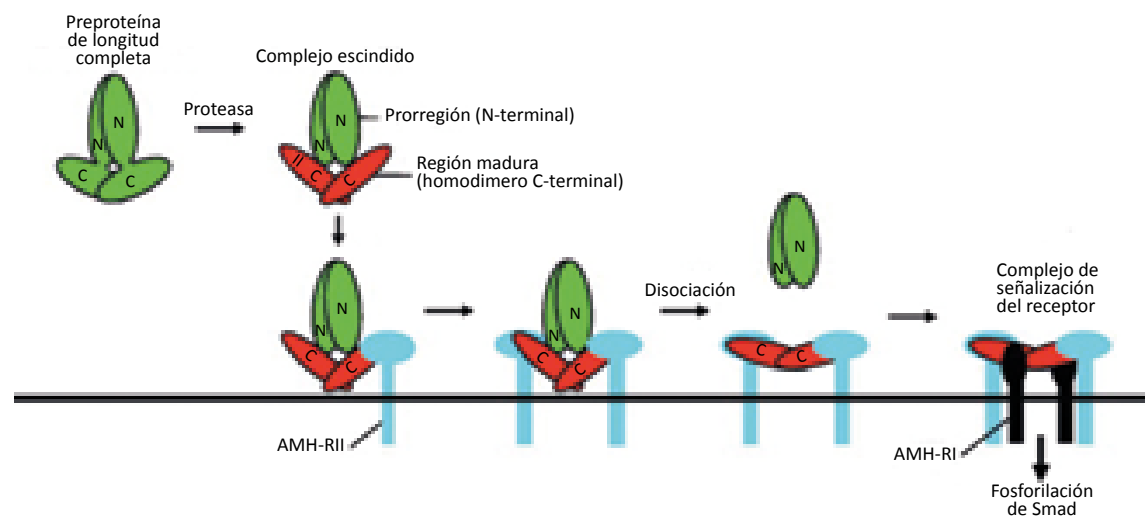

Figura 1. Procesamiento de la hormona antimülleriana y unión a su receptor, el AMHR II. Tomado y modificado de «Processing of anti-mullerian hormone regulates receptor activation by a mechanism distinct from TGF-beta» por N. di Clemente y colaboradores, 2010, Mol Endocrinol, 24, p. 2194. Copyright ${ }^{\circledR} 2010$ por The Endocrine Society [3]. AMH-RII = receptor tipo I de la hormona antimülleriana, AMH-RII = receptor tipo II específico para la hormona antimülleriana.

\section{Fisiología de la diferen- ciación sexual masculina}

Durante la vida fetal la diferenciación sexual masculina se produce antes de que el eje hipotálamo-hipófisis-testicular sea funcional. Específicamente, en los fetos masculinos, las células de Sertoli comienzan la secreción de la hormona antimülleriana hacia la séptima semana de gestación, cuando los túbulos seminíferos se han diferenciado. Una vez es producida, la hormona induce la regresión de los conductos de Müller, lo que facilita el desarrollo de los conductos de Wolff, quienes dan origen al epidídimo, los conductos deferentes y las vesículas seminales $[1,4,15]$. Por su parte, en el tejido intersticial testicular, las células de Leydig secretan los andrógenos, los cuales participan en la virilización genital interna y externa del feto [12].

Hacia la segunda mitad de la vida intrauterina, por acción de la hormona liberadora de gonadotropina (GnRH), producida en el hipotálamo, la hipófisis inicia la secreción de las gonadotropinas: la hormona luteinizante (LH), la cual va a regular la proliferación de las células de Leydig y la secreción de los andrógenos (testosterona), y la hormona folículo estimulante (FSH), que va a modular la proliferación de las células de Sertoli y la secreción de la hormona antimülleriana y la inhibina B [15-17]. Dentro del testículo, la testosterona actúa como un regulador autocrino y como un factor paracrino sobre las células de Sertoli; además, en circulación, ejerce acciones en diferentes órganos distantes, incluida la retroalimentación negativa sobre la secreción de la LH en la hipófisis. Por su parte, la inhibina B es la principal señal de retroalimentación negativa de la FSH hipofisaria (véase figura 2) [13].

Durante el primer mes de vida posnatal del varón los niveles de las hormonas del eje hipófisis-testicular aumentan [18]. Para el segundo y tercer mes la FSH, la LH y la testosterona alcanzan su pico máximo, disminuyen después del sexto mes a niveles muy bajos o indetectables [19] y se mantienen así durante el resto de la infancia y 


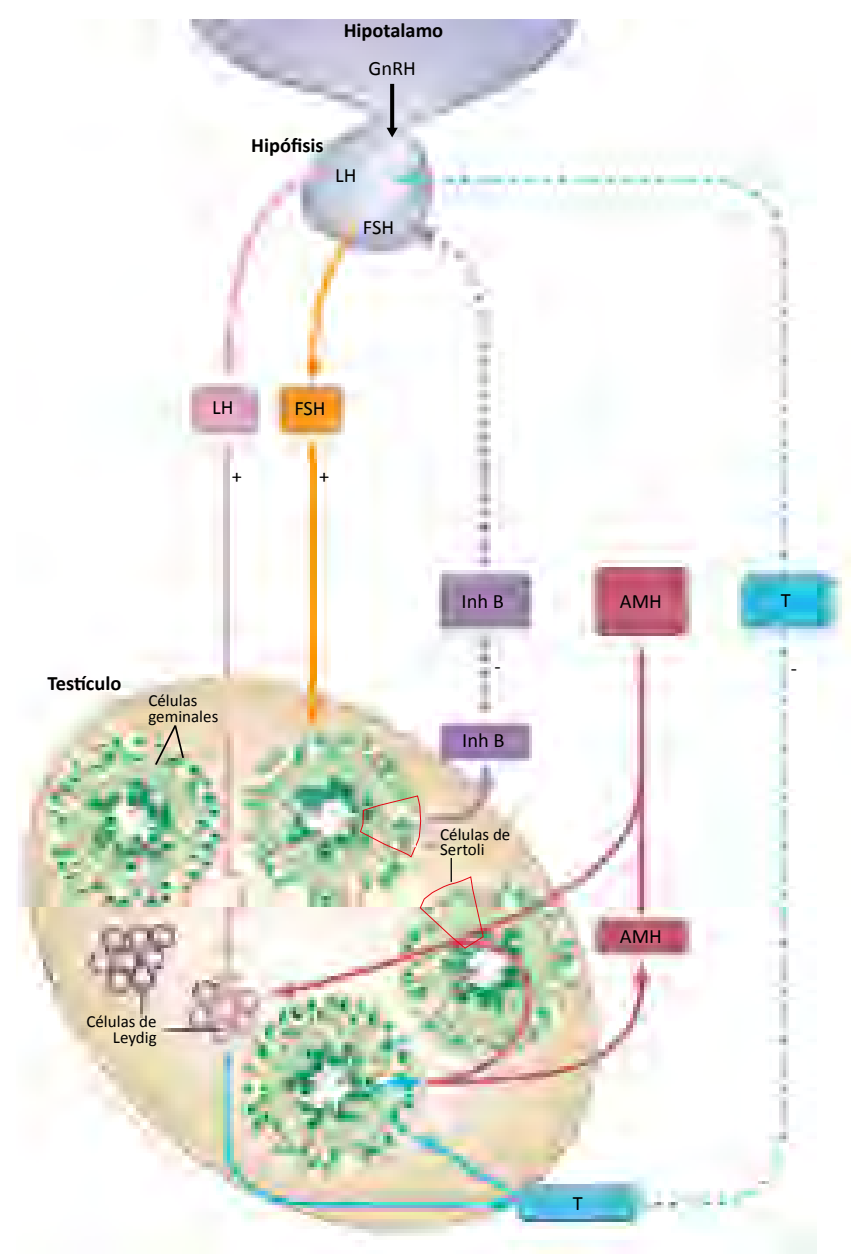

Figura 2. Eje hipófifis-testicular. Tomado y modificado de "The prepubertal testis: biomarkers and functions" por C. Valeri, H. F. Schteingart y R. A. Reya, 2013, Curr Opin Endocrinol Diabetes Obes, 20, p. 225. Copyright (C) 2013 por Wolters Kluwer Health y Lippincott Williams \& Wilkins. GnRH = hormona liberadora de gonadotropina, $\mathrm{LH}=$ hormona luteinizante, $\mathrm{FSH}=$ hormona folículo estimulante, $\mathrm{T}=$ testosterona, $\mathrm{AMH}=$ hormona antimülleriana, Inh B = inhibina $B$.

la niñez (véase figura 3A). Por tal razón, se considera que estos marcadores son poco informativos para evaluar la función de las células de Leydig antes de los nueve años de edad y requieren para esto de pruebas dinámicas que impliquen la estimulación con gonadotropina coriónica humana (hCG) o LH [20]. Por el contrario, los niveles séricos de la hormona antimülleriana [21], al igual que de la inhibina B [22], permanecen elevados desde el nacimiento hasta finalizar la infancia (véase figura 3A), lo que refleja que las células de Sertoli se encuentran funcionalmente activas y las hace marcadores útiles de la función gonadal en condiciones basales [20] y en respuesta al tratamiento con FSH durante esta etapa de vida [23].

Por su parte, desde el nacimiento hasta la infancia (8-10 años de edad) la proliferación de las células de Sertoli, inducida esencialmente por la FSH, produce un ligero aumento del volumen testicular que no es detectable mediante palpación y comparación con orquidómetro [24,25], pero que puede ser medido mediante ultrasonografía [26]. En la etapa puberal, definida clínicamente por un volumen testicular de $4 \mathrm{~mL}$, las células de Sertoli sufren un cambio de un estado 


\section{Utilidad clínica de la medición de la hormona antimülleriana en niños}
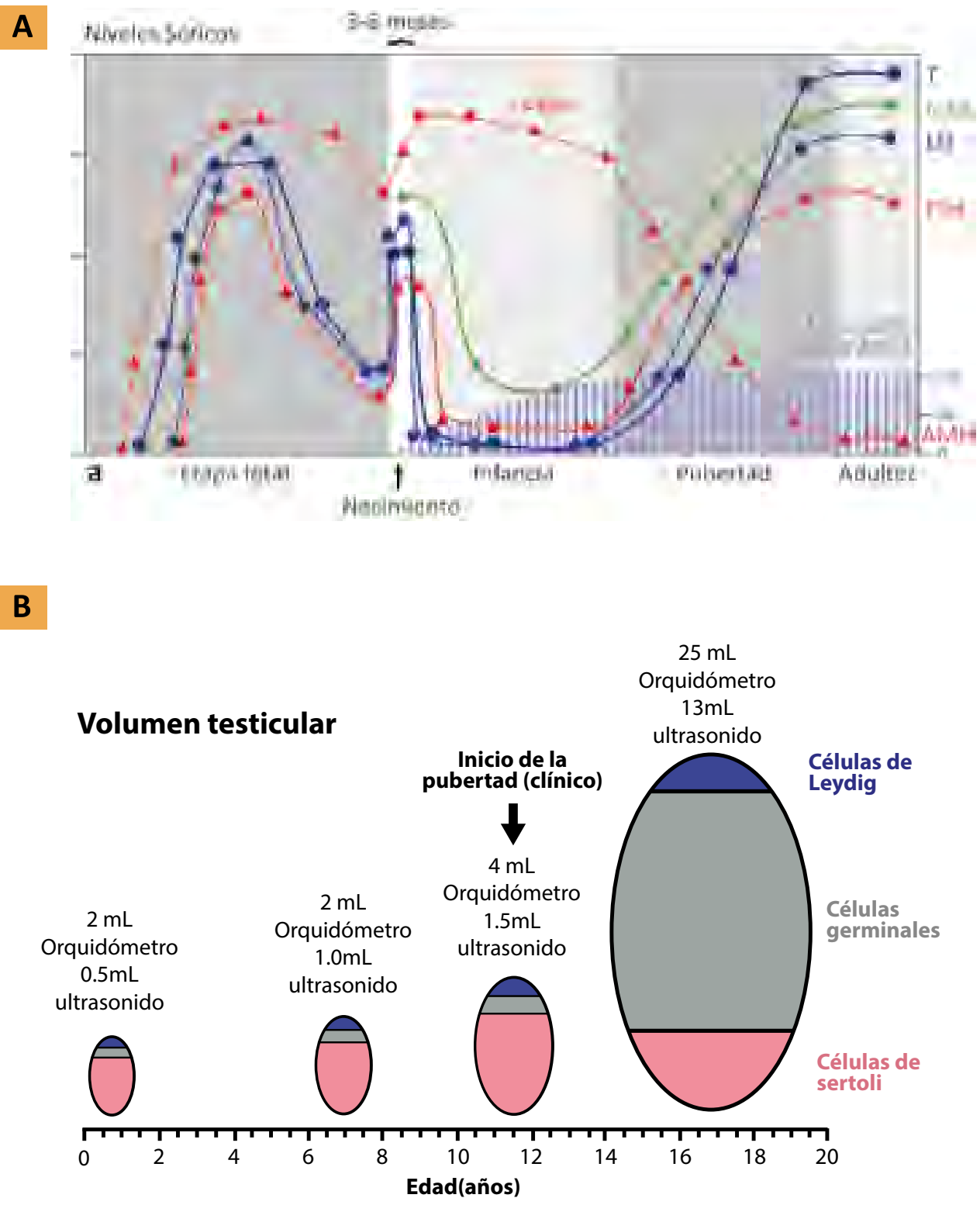

Figura 3. Desarrollo fisiológico del testículo. A. El eje de la izquierda esquematiza los niveles séricos de la hormona folículo estimulante (FSH), la hormona luteinizante (LH), la testosterona (T), la inhibina B (inh B) y la hormona antimülleriana $(\mathrm{AMH})$ desde antes del nacimiento hasta la adultez. El eje de la derecha muestra el porcentaje de células de Sertoli que expresan el receptor de andrógenos (AR). B. Incremento del volumen testicular durante las diferentes etapas de la vida, medido por ultrasonografía. Tomado de "Anti-Müllerian hormone as a marker of steroid and gonadotropin action in the testis of children and adolescents with disorders of the gonadal axis» por N.Y. Edelsztein y colaboradores, 2016, Int J Pediatr Endocrinol, 20, p. 3. Copyright ${ }^{\odot} 2016$ por los autores. Creative Commons Attribution 4.0 International License [4]. $\mathrm{LH}=$ hormona luteinizante, $\mathrm{FSH}=$ hormona folículo estimulante, $\mathrm{T}=$ testosterona, $\mathrm{AMH}=$ hormona antimülleriana, Inh B = inhibina B. 
inmaduro y proliferativo a uno maduro y en reposo, el cual es inducido por el aumento de la concentración de los andrógenos intratesticulares, coincidente con la disminución en la expresión de la hormona antimülleriana, para soportar la espermatogénesis [27], lo que produce un aumento drástico en el volumen testicular. Esta acción, por parte de los andrógenos, no se observa durante la etapa fetal ni en el primer año de vida, debido a que aún no hay expresión del receptor de andrógenos en las células de Sertoli $[6,13,17,28,29]$ (véase figura $3 \mathbf{A}$ y $3 \mathbf{3}$ ) .

\section{Fisiología de la hormo- na antimülleriana en el hombre}

Como ya se mencionó, el inicio de la expresión de la hormona antimülleriana por las células de Sertoli durante la vida fetal es independiente de la producción de las gonadotropinas, pero depende de múltiples factores de transcripción como el SOX9, el SF1, el GATA4, entre otros [15,30-33]. En los primeros meses de vida posnatal del varón, momento en el que el lactante se encuentra en el periodo de mini-pubertad, la hormona antimülleriana es producida por el estímulo de la FSH a nivel testicular a través de la inducción de la proliferación de las células de Sertoli y de la regulación positiva de su transcripción [4].

Para esto, la FSH se une a su receptor, el FSH$\mathrm{R}$, lo que activa la vía de transducción clásica que implica a la proteína Gsa, la adenilil ciclasa (AC) y la estimulación de la actividad de la proteína quinasa $A$ (PKA) por el adenosín monofosfato cíclico (AMPc), que lleva a la activación del promotor de la hormona antimüIleriana inicialmente por SOX9, lo cual desencadena la expresión de la hormona, seguido de otros factores de transcripción como SF1, GATA4, DAX1 y WT1 [32] que se unen, posteriormente, para aumentar la producción de la hormona a nivel testicular. Además, también participan otros factores como el NFKB y el AP2 (véase figura 4) [15,30-33].

Durante la infancia, en los varones, los niveles de la hormona antimülleriana alcanzan su pico máximo; cerca de los cuatro años disminuyen en un $20 \%$ y permanecen estables hasta la pubertad (entre los 10 y 12 años) $[9,34,35]$. En la pubertad los niveles de la hormona disminuyen entre el $80 \%$ y el $90 \%$ en respuesta al aumento de la concentración intratesticular de la testosterona $[6,28]$, la cual ejerce un efecto inhibitorio más fuerte que el efecto estimulante de la FSH (véase figura $3 \mathbf{A}$ y $\mathbf{5 A}$ ) $[28,36]$, que no se presenta durante el periodo fetal ni neonatal, pues, como ya se mencionó, para este momento no hay expresión del receptor de andrógenos en las células de Sertoli [37-39].

En contraste, en los fetos femeninos, en los que la ausencia de hormona antimülleriana conduce al desarrollo de los conductos de Müller de los cuales se derivan el útero, las trompas de Falopio y el tercio superior de la vagina, la hormona es identificable hacia la semana 36 de gestación, pero en niveles hasta 50 veces menores que los de los varones al momento del nacimiento. Durante la infancia, en las mujeres, el aumento gradual de los niveles de la hormona antimülleriana refleja el crecimiento de los folículos ováricos. Durante la adolescencia los niveles se estabilizan y posterior a los 25 años comienzan a declinar, hasta hacerse indetectables hacia los 45 años de edad (véase figura 5B) $[6,9,34,35,40,41]$. Tanto en los hombres como en las mujeres la hormona antimülleriana presenta una alta variabilidad interindividual (véase figura 4) [6]. 


\section{Utilidad clínica de la medición de la hormona antimülleriana en niños}

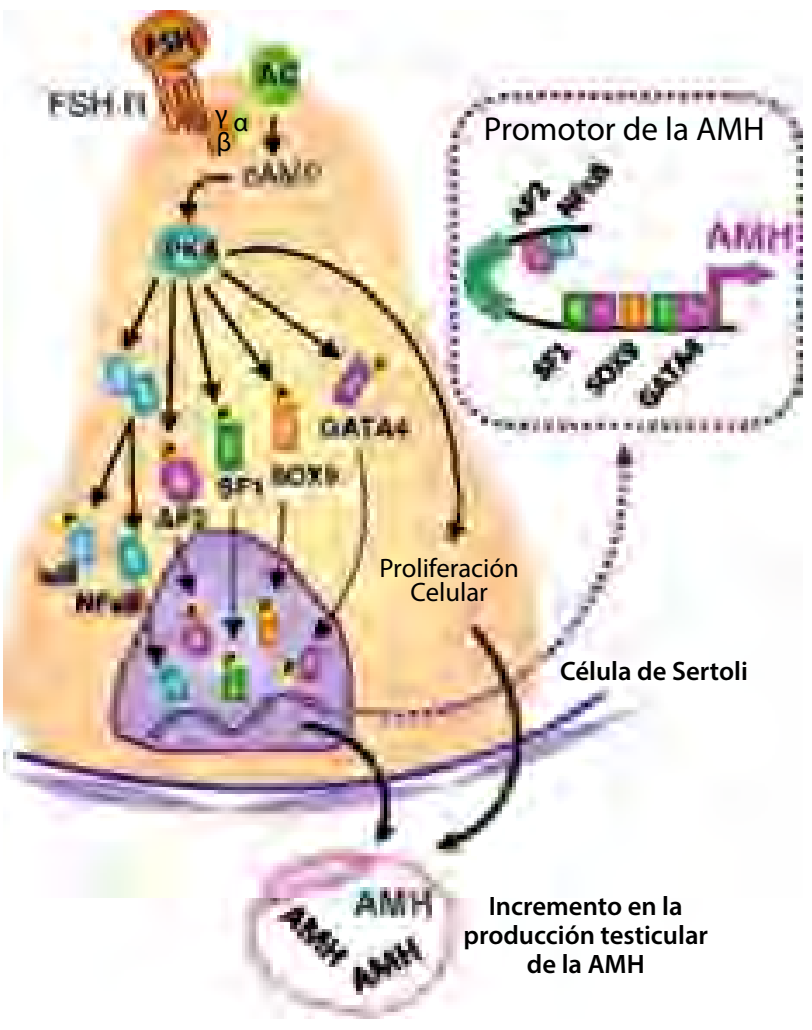

Figura 4. Hormona antimülleriana como marcador de la acción de la FSH en los testículos prepuberales. Tomado de "Anti-Müllerian hormone as a marker of steroid and gonadotropin action in the testis of children and adolescents with disorders of the gonadal axis" por N.Y. Edelsztein y colaboradores, 2016, Int J Pediatr Endocrinol, 20, p. 4. Copyright(C) 2016 Los autores. Creative Commons Attribution 4.0 International License [4]. FSH = hormona folículo estimulante, $\mathrm{FSH}-\mathrm{R}=$ receptor de la $\mathrm{FSH}, \mathrm{AC}=$ adenilil ciclasa, $\mathrm{AMPC}=$ adenosín monofosfato cíclico, PKA = proteína quinasa $\mathrm{A}, \mathrm{AMH}=$ hormona antimülleriana.

\section{A}

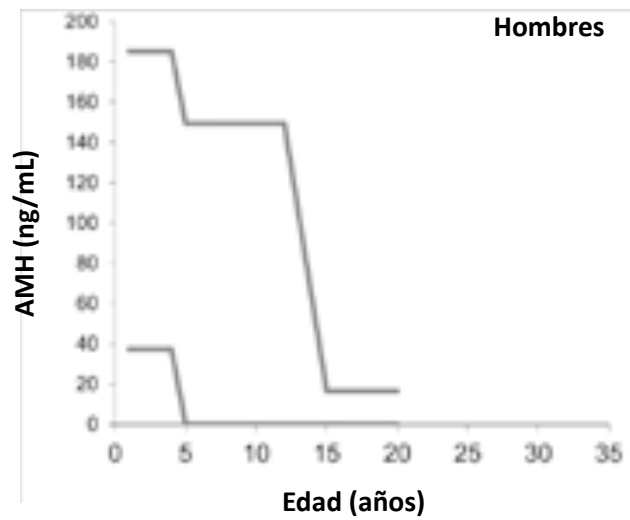

B

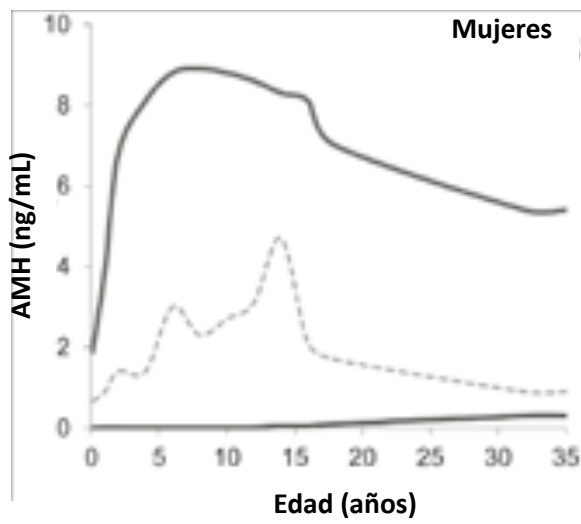

Figura 5. Nomograma de los niveles séricos de la hormona antimülleriana según la edad en hombres (A) y mujeres (B). La línea solida inferior corresponde al percentil 5 y la línea solida superior al percentil 95; la línea punteada representa el percentil 50 en las mujeres. Tomado y modificado de "Anti-mullerian hormone $(\mathrm{AMH})$ determinations in the pediatric and adolescent endocrine practice" por A. Weintraub y T. Eldar-Geva, 2017, Pediatr Endocrinol Rev, p. 365. CopyrightC 2017 por Y.S. Medical Media, Ltd. [6]. 


\section{Utilidad clínica de la hormona antimülleriana en los niños}

\section{Trastornos \\ de la diferenciación sexual}

La diferenciación de la gónada bipotencial es iniciada por la expresión del gen SRY en el cromosoma $Y$, que inicia una cascada de señalización que induce que se desarrolle en un testículo. Posteriormente, y secundario a la secreción de hormonas, como la testosterona y la hormona antimülleriana, por estos testículos, se genera la diferenciación de los genitales internos (las vesículas seminales, los conductos deferentes y el epidídimo), lo que involucra la regresión de los conductos de Müller y la proliferación de los conductos de Wolff, así como la diferenciación y la virilización de los genitales externos (véase figura 6) [42-44]. En caso de que la vía genética del desarrollo gonadal sea defectuosa, de modo que las funciones génicas se pierdan o se anulen, se producen trastornos de la diferenciación sexual [44].

Específicamente, los trastornos de la diferenciación sexual 46, XY representan un verdadero reto diagnóstico. Su incidencia aproximada es de un caso por cada 1.500 recién nacidos $y$, aunque no siempre es posible identificarlo al momento del nacimiento, se presenta como genitales mal diferenciados; posteriormente, puede ser identificada durante los estudios para el diagnóstico de pubertad retrasada, virilización anticipada o ginecomastia, infertilidad o tumores gonadales $[1,4,12,44]$.

Al enfrentarse a un trastorno de la diferenciación sexual $46, \mathrm{XY}$ se deben estudiar las posibles causas de la virilización insuficiente, que en términos generales puede ser debido a alteraciones a nivel gonadal, como la disgenesia gonadal o la aplasia de las células de Leydig, o secundario a defectos enzimáticos en la vía de la esteroidogénesis y de sus receptores $[1,4,12,44,45]$. En ambas condiciones los niveles de testosterona se encuentran disminuidos, por lo que los niveles séricos de la hormona antimülleriana son de gran ayuda para diferenciarlos, encontrándose elevada o normal en los casos de deficiencia androgénica, en donde la función testicular está conservada, y disminuidos en los de disgenesia gonadal, en donde los niveles son el reflejo del grado de disfunción de la gónada $[1,4,12,45]$.

Otra posible causa de virilización insuficiente es el síndrome de insensibilidad a los andrógenos, en el que se presenta alteración en la acción de los andrógenos sobre las gónadas, pero se conserva la actividad tanto de las células de Sertoli como de las de Leydig, que se refleja en niveles de la hormona antimülleriana, al igual que de los andrógenos, normales o incluso elevados. Por el contrario, en los casos de hipospadias aisladas los niveles de la hormona antimülleriana y la testosterona están normales, lo que indica que no hay disfunción testicular. En estos casos, en ausencia de otros signos de hipovirilización, se debe sospechar de un trastorno de la diferenciación sexual de tipo malformativo $[1,4,45,46]$.

Otra causa, aunque poco frecuente, de trastornos de la diferenciación sexual 46, $X Y$ es el síndrome de conductos müllerianos persistentes, en el que los conductos müllerianos permanecen en un varón $X Y$ normalmente virilizado, el cual se presenta de forma secundaria a mutaciones en el gen que codifica para la hormona anti- 


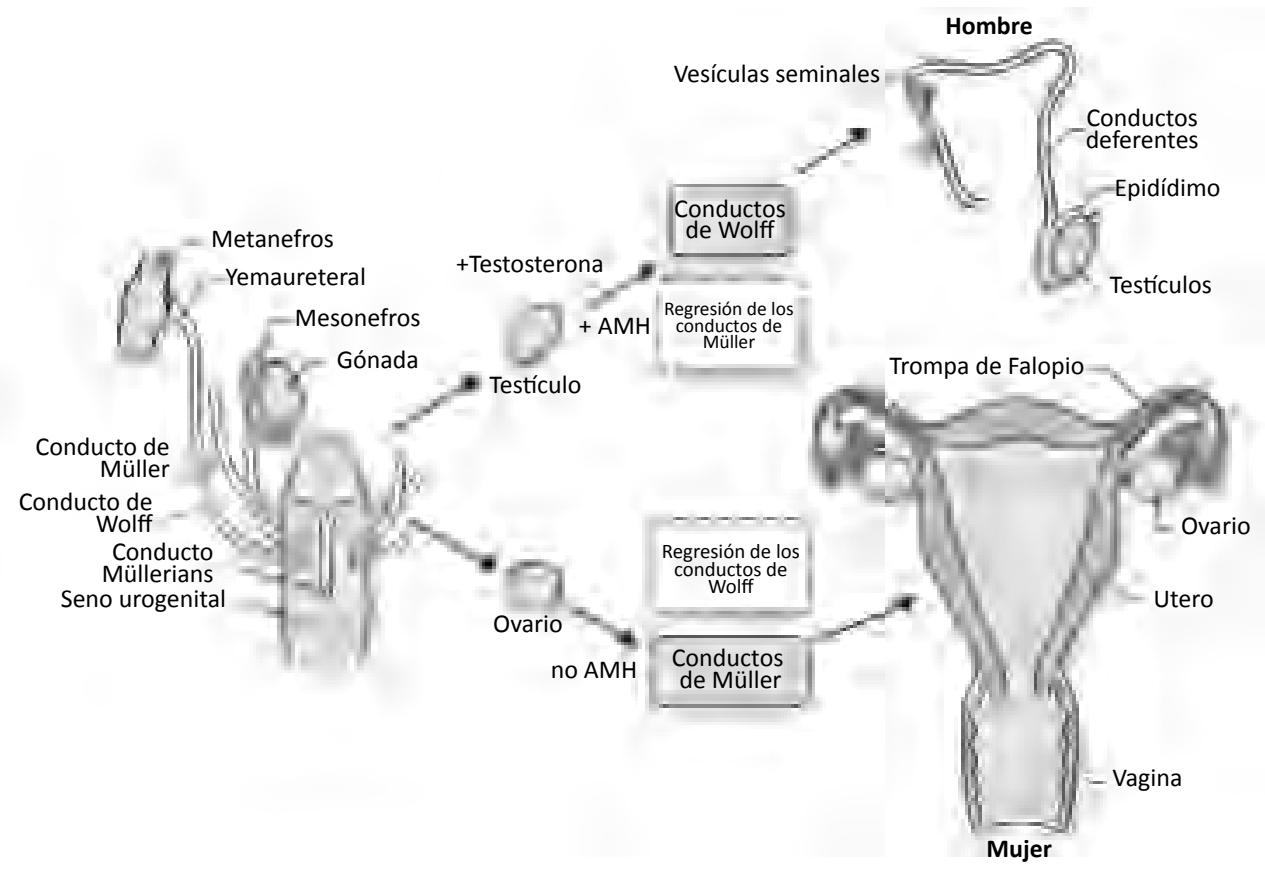

Figura 6. Desarrollo de los genitales internos masculinos y femeninos. Tomado y modificado de "Disorders of sex development (DSDs): An update" por H. Ostrer, 2014, Clin Endocrinol Metab, p. 1504. Copyright (C) 2014 por Endocrine Society [44].

mülleriana o para su receptor, el AMH-RII. En estos casos, los niveles de la hormona antimülleriana son útiles para diferenciar la etiología del síndrome, donde un resultado normal es indicativo de mutaciones del receptor, mientras que aquellos bajos o indetectables son sugestivos de mutaciones en el gen de la hormona $[9,11,30,47-50]$.

En cuanto a los trastornos de la diferenciación sexual 46, XX el uso de la medición de la hormona antimülleriana es mínimo; no obstante, los niveles por encima del rango normal para una niña permiten sospechar de un trastorno de la diferenciación sexual ovotesticular, y excluyen la presencia de una hiperplasia suprarrenal congénita, defectos de la aromatasa o tumores virilizantes $[4,12,51,52]$.

\section{Hipogonadismo central}

El hipogonadismo masculino en la edad pediátrica hace referencia a una disminución en la actividad gonadal esperada para la edad, que implica una secreción alterada de las hormonas por las células de Sertoli o por las células de Leydig o un trastorno de la espermatogénesis. Esta alteración se caracteriza principalmente por déficit de la testosterona y, clínicamente, por la ausencia de la adquisición de los caracteres sexuales secundarios e infertilidad. En el caso del hipogonadismo central la alteración se encuentra a nivel hipofisiario o hipotalámico, mientras que en el hipogonadismo primario la alteración se encuentra a nivel gonadal; este último, a diferencia de la edad adulta, rara vez es hipergonadotrópico durante la 
infancia. El hipogonadismo primario puede ser congénito (asociado a síndromes o alteraciones genéticas) o adquirido (secundario a traumas, radiaciones o tumores) [53-56].

Específicamente, se debe sospechar un hipogonadismo central cuando se encuentran algunas características clínicas asociadas a la criptorquidia, como el micropene, o coexistencia de otras deficiencias hormonales hipofisiarias [4]. Los bajos niveles de testosterona encontrados son reflejo de la ausencia de estimulación de las células de Leydig por parte de la LH [53-56]. En los individuos prepúberes y puberales con hipogonadismo central los niveles séricos de la hormona antimülleriana son bajos, debido a la falta del estímulo de las células de Sertoli por la FSH durante la vida fetal y neonatal [4,57-59], aunque los niveles dentro del rango de la normalidad no excluyen el diagnóstico.

Young y colaboradores (2005) [23] demostraron que en los pacientes con hipogonadismo central que eran tratados con FSH recombinante aumentaban los niveles de la hormona antimülleriana y que, al adicionar al tratamiento gonadotropina coriónica humana (hCG), dichos niveles disminuían drásticamente como respuesta al aumento de la testosterona intratesticular, lo que asemeja mejor los cambios fisiológicos observados en la pubertad. Esta regulación presentada ante la disminución de la hormona antimülleriana no se observa de la misma manera en los pacientes que reciben únicamente manejo con testosterona, debido, probablemente, a que los bajos niveles intratesticulares de la misma son insuficientes para generar una retroalimentación negativa $[4,23,59]$. Este hallazgo deja como mensaje que la hormona antimülleriana sérica también es una buena herramienta para evaluar la respuesta al tratamiento con FSH en los pacientes con hipogonadismo central $[1,4,23,59]$.

\section{Síndrome de Klinefelter}

El síndrome de Klinefelter es una de las causas más comunes de hipogonadismo primario de inicio tardío, asociado a un desorden cromosómico caracterizado por la existencia de un cromosoma $\mathrm{X}$ extra, cuya incidencia es de 150 por cada 100.000 varones. Este síndrome es causado por una aneuploidia de los cromosomas sexuales, donde se encuentra un cariotipo 47, XXY en el $80 \%$ de los casos. Aunque a nivel testicular se presentan células germinales, estas sufren un rápido proceso de degeneración, además de una deficiencia en la producción de testosterona, lo que lleva al hipogonadismo. Las características clínicas principales son ginecomastia, testículos pequeños y firmes, proporciones corporales eunucoides, azoospermia y niveles aumentados de gonadotropinas, con niveles disminuidos de testosterona [60-62]. En este caso no hay evidencia clínica del hipogonadismo hasta después de la pubertad.

En el síndrome de Klinefelter los niveles séricos de la hormona antimülleriana son normales durante la infancia y la pubertad temprana, al igual que los niveles de la inhibina B y la FSH. Entrada la pubertad los niveles séricos de la hormona antimülleriana disminuyen de forma fisiológica, secundario al aumento de la testosterona, tal como ocurre en los niños normales [63-66]. Posteriormente, se produce la disfunción progresiva de las células de Sertoli, lo que conduce a la disminución de la hormona antimülleriana a niveles extremadamente bajos o indetectables, congruente con la disminución de la inhibina B, el aumento de la FSH y un volumen testicular pequeño $[4,63]$. 


\section{Criptorquidia y anorquia}

La criptorquidia es la anomalía genética más común en el recién nacido masculino, caracterizada por la ausencia del testículo en su posición escrotal normal y que afecta aproximadamente al $5 \%$ de los recién nacidos a término y hasta el $45 \%$ de los recién nacidos pretérmino. Al finalizar el primer año de vida hasta el $70 \%$ de los casos pueden resolverse de forma espontánea [67-70]. En caso de que no hayan descendido se recomienda realizar orquidopexia o intervención hormonal, ya que los testículos no descendidos están asociados con malignidad y problemas de fertilidad debido a la reducción del número de espermatagonias y madurez de los espermatocitos [71].

Esta condición es considerada un signo clínico que puede ser consecuencia de un hipogonadismo primario o uno central, o de defectos anatómicos de la región inguinal o la pared abdominal, es decir, no debidos a hipogonadismo; además, puede estar asociado a una función normal o alterada de las células de Sertoli $[4,72]$. De esta manera, al enfrentarse a un paciente con gónadas no palpables se recomienda determinar la presencia de tejido testicular funcional a nivel intraabdominal. No obstante, la medición de las gonadotropinas séricas basales no es de gran utilidad para este fin, al encontrarse en niveles normales, incluso en los pacientes con ausencia de ambos testículos (anorquia) [73]. De igual manera, los ultrasonogramas y la resonancia magnética no detectan el $10 \%$ al $20 \%$ de las gónadas intraabdominales [74,75].

Por su parte, los niveles detectables en suero de la hormona antimülleriana son altamente sugestivos de la existencia de tejido testicular funcional en niños prepuberales $[45,76,77]$. Incluso, Lee y colaboradores
(1997) [76] demostraron que en los niños con gónadas no palpables bilaterales la hormona antimülleriana permite diferenciar de forma adecuada la presencia de testículos no descendidos (criptorquidia), cuando sus niveles se encuentran en un rango normal, de la disfunción de las células de Sertoli, en la que están bajos, y la anorquia, en la cual son indetectables, de forma más sensible y específica que la testosterona. Estos hallazgos fueron confirmados más adelante por Misra y colaboradores (2002), en un estudio más amplio en niños con criptorquidia [77]. De esta manera, se considera que la medición de la hormona antimülleriana podría reemplazar otras pruebas hormonales como la prueba dinámica de estimulación con gonadotropinas para confirmar la presencia o ausencia de testículos $[1,4,72,77]$.

\section{Macroorquidismo prepuberal}

El macroorquidismo, definido como un volumen y desarrollo testicular mayor que el correspondiente para la edad, se ha informado, en ausencia de características sexuales secundarias dependientes de la secreción de andrógenos, como una forma de presentación del síndrome de McCune-Albright. En este, la mutación activadora somática del gen GNAS1, que codifica para la proteína $\mathrm{Gs} \alpha$, involucrada en la vía de transducción del receptor de la FSH, resulta en una hiperproliferación e hiperfunción de las células de Sertoli, que lleva al aumento en la producción de la hormona antimülleriana [78].

\section{Pubertad precoz}

La pubertad precoz está descrita como el desarrollo de los caracteres sexuales secundarios en un varón antes de la edad habitual de aparición, en general, antes de los nueve años. La incidencia anual de esta con- 
dición en niños es de aproximadamente de uno por cada 100.000 , lo cual corresponde a 15 veces menos de lo que se presenta en niñas [79-81]. Durante la pubertad precoz los niveles de la hormona antimülleriana disminuyen igual a como ocurre durante la pubertad normal, con el mismo patrón de retroalimentación negativa secundaria al aumento en los niveles de andrógenos [4].

La medición de la hormona antimülleriana es especialmente útil en aquellos niños con signos no tan claros de pubertad precoz, como un aumento del volumen testicular a $3 \mathrm{~mL}$ sin crecimiento peneano, en quienes los niveles de gonadotropinas y de testosterona pueden no estar aumentados [4]. Grinspon y colaboradores (2013) [82] mostraron que la hormona antimülleriana también es útil durante el seguimiento del tratamiento con análogos de la hormona liberadora de gonadotropina (GnRH), en niños con pubertad precoz central, en los que sus niveles regresen a los normales para la etapa prepuberal.

No obstante, en los niños menores de un año la hormona antimülleriana no muestra utilidad, ya que sus niveles no disminuyen debido a la falta de expresión de los receptores androgénicos en las células de Sertoli en la primera infancia, lo que las hace transitoriamente insensibles a los andrógenos [82]. De igual forma, se ha demostrado que la falta de adherencia al tratamiento con análogos de la hormona liberadora de gonadotropina genera que los niveles de la hormona antimülleriana no se normalicen como se esperaba, debido a la inhibición intermitente de la producción de testosterona [28].

\section{Pubertad retrasada}

Se habla de pubertad retrasada en los varones cuando hay ausencia del aumento en el tamaño testicular por encima de 4 $\mathrm{mL}$ alrededor de los 14 años de edad, sin tener en cuenta la presencia o ausencia de vello púbico para definirla. Las principales causas de esta alteración son: a) retraso constitucional del desarrollo, un estado no patológico en el cual la madurez del eje hipotálamo-hipófisis-gónada está retardada, b) hipogonadismo hipogonadotrófico, generalmente secundaria a una alteración a nivel central que resulta en niveles disminuidos de FHS y $\mathrm{LH}, \mathrm{y} \mathrm{c}$ ) hipogonadismo hipergonadotrófico, en el cual hay una incapacidad a nivel gonadal para producir los esteroides sexuales y está caracterizado por elevados niveles de FHS y LH [83-85].

En los pacientes que presentan un retraso constitucional del desarrollo, dado que su estado es eugonadal, los niveles de la hormona antimülleriana se encuentran en rangos normales prepuberales [57]. Es así como Rohayem y colaboradores (2015) [86] demostraron que la medición de la hormona antimülleriana es útil al momento de diferenciar entre un retraso constitucional del desarrollo y un hipogonadismo central, en cuyo caso los niveles de la hormona están por encima de lo esperado para la edad, ya que no hay regulación por parte de la testosterona intratesticular, pero disminuidos para lo esperado en los niños prepuberales, pues no hay estimulación de las células de Sertoli por la FSH.

\section{Tumor de las células de Sertoli}

La inmunohistoquímica de la hormona antimüllerina es útil para la identificación del origen de los tumores testiculares, ya que se ha encontrado expresada en los tumores de las células de Sertoli, los tumores primarios o metástasicos de células de la 
granulosa de los testículos, incluso en la proliferación intratubular de las células de Sertoli, considerada una etapa inicial de los tumores de estas células. En el diagnóstico inicial de estos tumores la determinación única de la hormona antimülleriana sérica no es útil, debido a los altos niveles de la hormona que se presentan normalmente en la edad prepuberal; no obstante, un aumento paulatino de los niveles de la hormona antimülleriana podría ser sugestivo de una lesión progresiva $[4,87,88]$.

\section{Toxicidad gonadal inducida por quimio o radioterapia}

Actualmente, debido a los avances en oncología, se ha presentado un incremento en el número de pacientes sobrevivientes al cáncer. No obstante, se conoce que uno de cada dos pacientes sobrevivientes al cáncer sufre de alguna alteración endocrina a lo largo de su vida, siendo las alteraciones en el eje de crecimiento y en el gonadal las de mayor frecuencia, en cuyo caso se deben tener presentes los efectos adversos que produce el tratamiento en la fertilidad. La toxicidad gonadal va a depender del tipo de terapia utilizada, la dosis y la edad del paciente $[89,90]$.

En los pacientes tratados con terapia gonadotóxica (cisplatino o busulfán) los niveles de la hormona antimülleriana pueden encontrarse disminuidos, al igual que los de la inhibina B, y los de la FSH estar aumentados [91]. Cuny y colaboradores (2011) [92] demostraron que la medición de la hormona antimülleriana es de utilidad para determinar la presencia de una deficiencia gonadal primaria por ausencia de gonadotropinas, inducida en pacientes expuestos a tratamiento con radioterapia.

\section{Medición de los niveles séricos de la hormoma antimülleriana}

Los primeros estudios sobre la medición de la hormona antimülleriana para la evaluación de la función testicular durante la infancia fueron realizados en los años noventa [93-95], los cuales utilizaban ensayos inmunoabsorbentes ligados a enzimas (ELISA; del inglés, Enzyme-Linked Immuno-Sorbent Assay) que incluían dos anticuerpos monoclonales, pero que mostraban variabilidad debido a su almacenamiento e inestabilidad al refrigerado. En el año 2005 se desarrolló una ELISA más sensible y específica que usaba un par de anticuerpos de captura y detección contra la hormona antimülleriana [96]. Posteriormente se desarrollaron dos tipos de ensayos, el Immunotech (IOT; Beckman-Coulter, California, Estados Unidos) y el Diagnosctic Systems Lab (DSL; Diagnostic Systems Laboratories Inc., Texas, Estados Unidos), los cuales utilizaban pares de anticuerpos diferentes y distintos estándares de calibración, sin un adecuado patrón internacional, por lo que al compararlos sus resultados podían variar hasta en un 30\% [97].

En los últimos años se logró consolidar estos dos métodos en uno solo, conocido como Gen II, el cual utiliza unos pares de anticuerpos dirigidos contra un epítope en la región madura de la hormona antimülleriana, lo que evita que los niveles en la muestra se afecten por la proteólisis de la hormona $[98,99]$. Este método era, hasta hace poco, el único disponible, pero recientemente se han desarrollado algunos estuches comerciales con una buena correlación con el Gen II [100]; estos son: el estuche AMH/ MIS ELISA ultrasensible de Ansh Labs (Texas, Estados Unidos) [101] y el inmunoensayo de 
electroquimioluminiscencia Elecsys ${ }^{\circledR}$ AMH de Roche Diagnostics International Ltd (RischRotkreuz, Suiza) [102]. Estos dos ensayos, en general, son comparables: presentan coeficientes de correlación por encima de 0,9, (Elecsys ${ }^{\circledR}$ frente Gen II =0,903 y ELISA ultrasensible frente Gen II =0,917), coeficientes de variación intraensayo de 0,5\% a 1,4\% para el Elecsys ${ }^{\circledR}$ y $1,4 \%$ a $5,4 \%$ para la ELISA ultrasensible, coeficientes de variación interensayo de $0,7 \%$ a $1,9 \%$ para el Elecsys ${ }^{\circledR}$ y $6,2 \%$ a $13,5 \%$ para la ELISA ultrasensible [100].

\section{Valores de referencia de la hormona antimülleriana en varones}

Actualmente, en nuestro medio, particularmente en el Laboratorio Clínico Hematológico (Medellín, Colombia) se cuenta con el estuche AMH/MIS ELISA ultrasensible de Ansh Labs para la medición de la hormona antimülleriana que consiste en un ensayo inmunoabsorbente ligado a enzimas (ELISA) de tipo sándwich, de tres pasos, que permite la medición cuantitativa de la hormona antimülleriana en suero y otros fluidos humanos [101].

En el artículo publicado en el anterior número de MEDICINA \& LABORATORIO se describieron las condiciones preanalíticas para esta prueba, su fundamento, las características analíticas de la misma y los valores de referencia en las mujeres sanas según su edad [14]. Como se mencionó en dicho manuscrito, actualmente, no se ha establecido un rango de referencia universal para la hormona antimülleriana, por lo que cada laboratorio debe plantear sus propios valores de acuerdo con el método usado y la población de estudio, teniendo en cuenta las variaciones que presentan los niveles de la hormona según la edad y el sexo.
El estuche AMH/MIS ELISA ultrasensible expresa los valores de la hormona antimülleriana en $\mathrm{ng} / \mathrm{mL}$. Para los hombres sanos se han establecido como normales, de acuerdo a la edad, los siguientes [101]:

Menores de 3 días: 25,9 ng/mL a 69,1 $\mathrm{ng} / \mathrm{mL}$

Menores de 3 meses: $24,2 \mathrm{ng} / \mathrm{mL}$ a $275,5 \mathrm{ng} / \mathrm{mL}$

Entre 1 y 11 años: $38,2 \mathrm{ng} / \mathrm{mL}$ a $332,4 \mathrm{ng} / \mathrm{mL}$

Entre 12 y 20 años: 1,1 ng/mL a $143,6 \mathrm{ng} / \mathrm{mL}$

Mayores de 20 años: 0,6 ng/mL a $17,7 \mathrm{ng} / \mathrm{mL}$

\section{Interpretación de resultados}

Igual que todas las pruebas de laboratorio, la medición de la hormona antimülleriana por sí sola no es suficiente para establecer un diagnóstico particular en los hombres a los que se les determina. Los resultados se deben interpretar a la luz de los hallazgos clínicos y los resultados de otras pruebas pertinentes. En la tabla 2 se describen los niveles séricos de la hormona antimülleriana para las distintas presentaciones clínicas en que su uso es aplicable en el hombre y en la figura 7 se esquematiza la producción testicular de la hormona antimülleriana en condiciones normales y patológicas.

\section{Conclusiones}

La hormona antimülleriana, cuyo papel inicialmente se remontaba a la diferenciación sexual del feto, donde favorece la aparición de los genitales internos masculinos, hoy en 


\begin{tabular}{|c|c|c|c|c|}
\hline \multirow[t]{2}{*}{ Signo clínico } & \multicolumn{4}{|c|}{ Niveles séricos de la hormona antimülleriana } \\
\hline & Indetectables & Bajos & Normales & Altos \\
\hline Criptorquidia & Anorquia & $\begin{array}{l}\text { Hipogonadismo pri- } \\
\text { mario o central }\end{array}$ & $\begin{array}{l}\text { Descarta disgenesia } \\
\text { gonadal }\end{array}$ & N.A. \\
\hline Micropene & $\begin{array}{l}\text { Regresión testicular } \\
\text { fetal }\end{array}$ & $\begin{array}{l}\text { Hipogonadismo pri- } \\
\text { mario o central }\end{array}$ & $\begin{array}{l}\text { Micropene malfor- } \\
\text { mativo }\end{array}$ & N.A. \\
\hline Pubertad retrasada & $\begin{array}{l}\text { Gonadectomía bilateral } \\
\text { Regresión testicular }\end{array}$ & $\begin{array}{l}\text { Hipogonadismo pri- } \\
\text { mario o central }\end{array}$ & $\begin{array}{l}\text { Retardo constitucional } \\
\text { del desarrollo }\end{array}$ & N.A. \\
\hline Pubertad precoz & N.A. & $\begin{array}{l}\text { Pubertad precoz } \\
\text { central } \\
\text { Testotoxicosis } \\
\text { Tumor de las células } \\
\text { de Leydig }\end{array}$ & $\begin{array}{l}\text { Hiperplasia suprarre- } \\
\text { nal congénita } \\
\text { Tumor adrenal secre- } \\
\text { tor de andrógenos } \\
\text { Exposición exógena a } \\
\text { andrógenos }\end{array}$ & N.A. \\
\hline $\begin{array}{l}\text { Macroorquidismo } \\
\text { prepuberal }\end{array}$ & N.A. & N.A. & N.A. & $\begin{array}{l}\text { Síndrome } \\
\text { de McCune- } \\
\text { Albright }\end{array}$ \\
\hline $\begin{array}{l}\text { Trastornos de la } \\
\text { diferenciación } \\
\text { sexual }\end{array}$ & $\begin{array}{l}46, \mathrm{XY} \text { disgenesia gona- } \\
\text { dal completa } \\
\text { Síndrome de conduc- } \\
\text { tos müllerianos persis- } \\
\text { tentes (mutación en } \\
\text { el gen de la hormona } \\
\text { antimülleriana) }\end{array}$ & $\begin{array}{l}46, \mathrm{XY} \text { disgenesia } \\
\text { gonadal parcial } \\
\text { Disgenesia gonadal del } \\
\text { cromosoma sexual } \\
\text { Trastorno del desarro- } \\
\text { llo sexual ovotesticular }\end{array}$ & $\begin{array}{l}\text { Defecto en la síntesis } \\
\text { de los andrógenos } \\
\text { Insensibilidad a los } \\
\text { andrógenos } \\
46, X Y \text { malformativo } \\
46, X X \text { varón (testi- } \\
\text { cular) } \\
\text { Síndrome de conduc- } \\
\text { tos müllerianos persis- } \\
\text { tentes (mutación en } \\
\text { el gen del receptor de } \\
\text { la hormona antimü- } \\
\text { lleriana) }\end{array}$ & $\begin{array}{l}\text { Defecto en } \\
\text { la síntesis de } \\
\text { los andróge- } \\
\text { nos } \\
\text { Insensibi- } \\
\text { lidad a los } \\
\text { andrógenos }\end{array}$ \\
\hline \multicolumn{5}{|c|}{$\begin{array}{l}\text { N.A. = No Aplica } \\
\text { Tomado de "Anti-Müllerian hormone as a marker of steroid and gonadotropin action in the testis of children and adolescents } \\
\text { with disorders of the gonadal axis" por N.Y. Edelsztein y colaboradores, 2016, Int J Pediatr Endocrinol, 20, p. 3. Copyright } \odot \\
2016 \text { por los autores. Creative Commons Attribution } 4.0 \text { International License [4]. }\end{array}$} \\
\hline
\end{tabular}

día es una herramienta útil en diversas condiciones patológicas en el niño al lograr evaluar la función testicular a nivel prepuberal e incluso reemplazar las pruebas de estímulo con hCG. Además, es de ayuda en el diagnóstico de los trastornos de la diferenciación sexual, las criptorquidias, las alteraciones de la pubertad y en el hipogonadismo [1,4,6,9]. Por lo anterior, es de suma importancia conocer su regulación y comportamiento a través de las diferentes etapas de la vida y en las diferentes alteraciones clínicas en que su uso es aplicable en los varones para hacerlo de forma adecuada.
A la fecha no se dispone de un método estándar de referencia, ni de una norma internacional que unifique el proceso de medición de la hormona antimülleriana de forma rutinaria mediante el uso de los diferentes métodos disponibles, que permita establecer los valores de referencia universales de esta hormona, con una significancia clínica para las diversas aplicaciones que posee $[100,103]$. A pesar de esto, el estuche AMH/ MIS ELISA ultrasensible, ajustado a las condiciones de cada laboratorio y población de estudio, representa una herramienta útil para la cuantificación de los niveles de la 


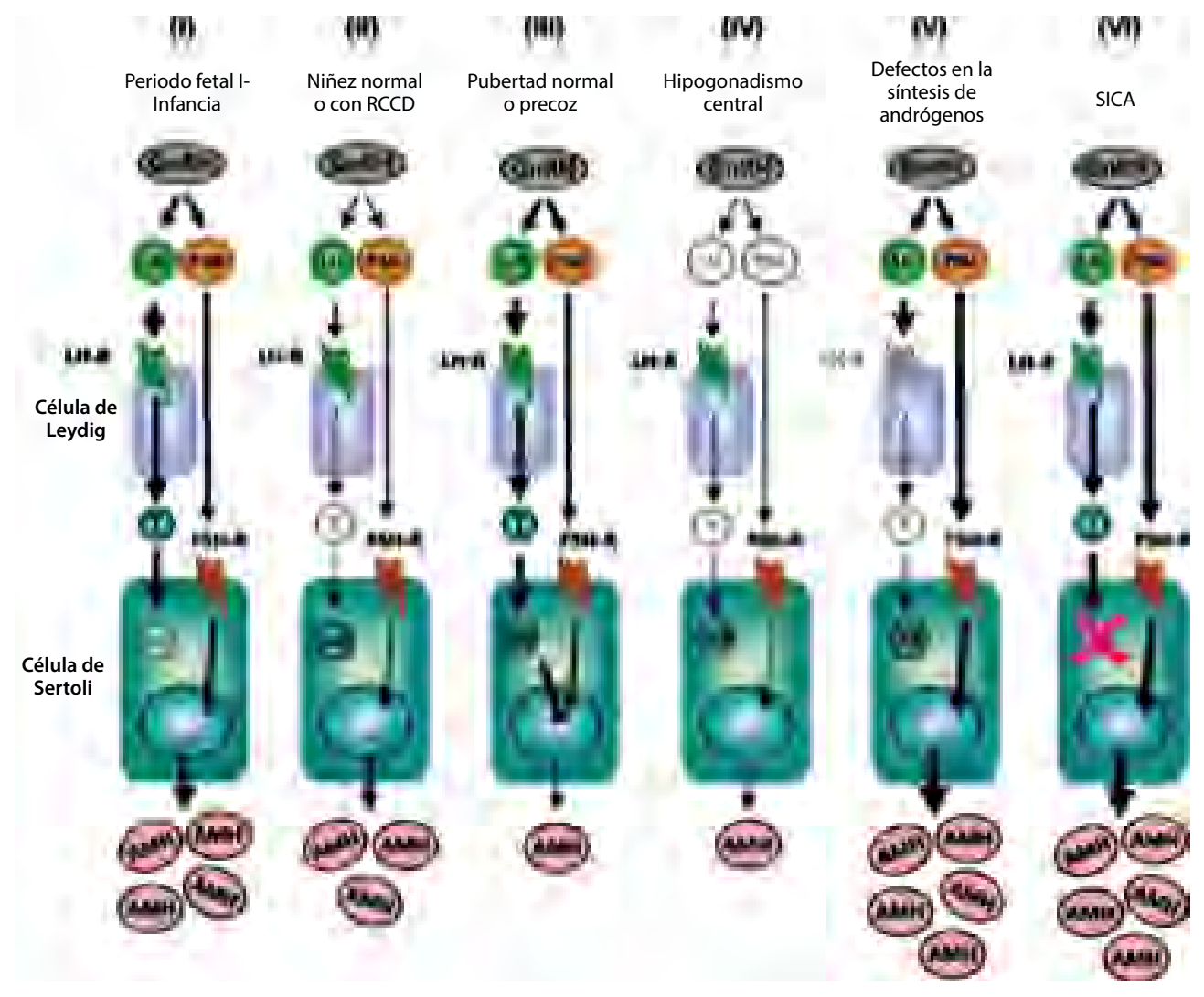

Figura 7. Producción testicular de la hormona antimülleriana en condiciones normales y patológicas, y su regulación por la FSH y la testosterona. I. Durante el periodo fetal y la infancia el eje hipotalámicogonadal está activo, la FSH estimula la producción de la hormona antimülleriana, pero la testosterona no inhibe su expresión pues aún no se ha expresado en las células de Sertoli el receptor de andrógenos. II. Durante la niñez normal o con retraso constitucional de crecimiento y desarrollo el eje hipotálamogonadal esta quiescente, por lo que no se afecta la producción basal de la hormona antimülleriana en esta etapa. III. Durante la pubertad, tanto normal como precoz, hay inhibición de la producción de la hormona antimülleriana por las altas concentraciones de la testosterona intratesticular, que supera la estimulación por la FSH, lo que se refleja en niveles séricos de la hormona antimülleriana disminuidos. IV. En el hipogonadismo central solo se tendrá producción basal de la hormona antimülleriana, sin estimulación por la FSH ni inhibición por la testosterona, lo que se refleja en niveles séricos de la hormona antimülleriana bajos. $\vee$ y VI. En los defectos de la síntesis de los andrógenos (V) o en el síndrome de insensibilidad completa a los andrógenos (VI) los niveles de la hormona antimülleriana se encuentran elevados, pues no hay inhibición por parte de la testosterona para contrarrestar la estimulación por la FSH. Tomado de "Anti-müllerian hormone as a marker of steroid and gonadotropin action in the testis of children and adolescents with disorders of the gonadal axis" por N.Y. Edelsztein y colaboradores, 2016, Int J Pediatr Endocrinol, 20, p. 3. Copyright (C) 2016 por los autores. Creative Commons Attribution 4.0 International License [4]. GnRH = hormona liberadora de gonadotropina, LH = hormona luteinizante, $\mathrm{FSH}=$ hormona folículo estimulante, $\mathrm{LH}-\mathrm{R}=$ receptor de la $\mathrm{LH}, \mathrm{T}=$ testosterona, $\mathrm{FSH}-\mathrm{R}=$ receptor de la $\mathrm{FSH}, \mathrm{AR}=$ receptor de andrógenos, $\mathrm{AMH}=$ hormona antimülleriana, $\mathrm{RCCD}=$ retraso constitucional de crecimiento y desarrollo, SICA = síndrome de insensibilidad completa a los andrógenos. 
hormona antimülleriana, con un buen desempeño y validez, y disponible en nuestro medio para la medición de la función testicular en los hombres, con aplicabilidad clínica.

El uso de la prueba de la hormona antimülleriana en las alteraciones del eje gonadal en los niños aún tiene mucho camino que recorrer, dado que su aplicación clínica para estas condiciones es reciente $y$, anteriormente, estaba limitado a la fertilidad femenina. En la actualidad, con la estandarización de la prueba y el mayor conocimiento generado por las diferentes investigaciones en el tema, se puede ampliar aún más el uso de la prueba en beneficio de los pacientes.

\section{Bibliografía}

1. Josso N, Rey RA, Picard J-Y. Anti-müllerian Hormone: A Valuable Addition to the Toolbox of the Pediatric Endocrinologist. Int J Endocrinol 2013; 2013: 12.

2. Pepinsky RB, Sinclair LK, Chow EP, Mattaliano RJ, Manganaro TF, Donahoe PK, et al. Proteolytic processing of mullerian inhibiting substance produces a transforming growth factor-beta-like fragment. J Biol Chem 1988; 263: 18961-18964.

3. di Clemente $\mathbf{N}$, Jamin SP, Lugovskoy A, Carmillo P, Ehrenfels C, Picard JY, et al. Processing of anti-mullerian hormone regulates receptor activation by a mechanism distinct from TGF-beta. Mol Endocrinol 2010; 24: 21932206.

4. Edelsztein NY, Grinspon RP, Schteingart HF, Rey RA. Anti-Mullerian hormone as a marker of steroid and gonadotropin action in the testis of children and adolescents with disorders of the gonadal axis. Int J Pediatr Endocrinol 2016; 2016: 20.

5. Lee MM, Donahoe PK. Mullerian inhibiting substance: a gonadal hormone with multiple functions. Endocr Rev 1993; 14: 152-164.

6. Weintraub A, Eldar-Geva T. Anti-Mullerian Hormone (AMH) Determinations in the Pediatric and Adolescent Endocrine Practice. Pediatr Endocrinol Rev 2017; 14: 364-370.

7. Imbeaud S, Faure E, Lamarre I, Mattei MG, di Clemente $\mathbf{N}$, Tizard $\mathbf{R}$, et al. Insensitivity to anti-mullerian hormone due to a mutation in the human anti-mullerian hormone receptor. Nat Genet 1995; 11: 382-388.

8. Josso N, Clemente N. Transduction pathway of anti-Mullerian hormone, a sex-specific member of the TGF-beta family. Trends Endocrinol Metab 2003; 14: 91-97.

9. Lindhardt-Johansen $\mathrm{M}$, Hagen $\mathrm{CP}$, Johannsen $\mathrm{TH}$, Main KM, Picard J-Y, Jorgensen A, et al. Anti-müllerian Hormone and Its Clinical Use in Pediatrics with Special Emphasis on Disorders of Sex Development. Int J Endocrinol
2013; 2013: 10.

10. Visser J. AMH signaling: From receptor to target gene. Mol Cell Endocrinol 2003; 211: 65-73.

11. di Clemente N, Belville C. Anti-Mullerian hormone receptor defect. Best Pract Res Clin Endocrinol Metab 2006; 20: 599-610.

12. Rey RA, Grinspon RP. Normal male sexual differentiation and aetiology of disorders of sex development. Best Pract Res Clin Endocrinol Metab 2011; 25: 221-238.

13. Valeri C, Schteingart HF, Rey RA. The prepubertal testis: biomarkers and functions. Curr Opin Endocrinol Diabetes Obes 2013; 20: 224-233.

14. Henao-Ochoa C, Lasprilla-Tovar JD, Alfaro-Velásquez JM, Campuzano-Maya G. Utilidad clínica de la medición de la hormona antimülleriana en las mujeres. Medicina \& Laboratorio 2017; 23: 213-236.

15. Lasala C, Carre-Eusebe D, Picard JY, Rey R. Subcellular and molecular mechanisms regulating anti-Mullerian hormone gene expression in mammalian and nonmammalian species. DNA Cell Biol 2004; 23: 572-585.

16. Lasala C, Schteingart HF, Arouche N, Bedecarras P, Grinspon RP, Picard JY, et al. SOX9 and SF1 are involved in cyclic AMP-mediated upregulation of anti-Mullerian gene expression in the testicular prepubertal Sertoli cell line SMAT1. Am J Physiol Endocrinol Metab 2011; 301: E539547.

17. Lukas-Croisier C, Lasala C, Nicaud J, Bedecarras P, Kumar TR, Dutertre M, et al. Follicle-stimulating hormone increases testicular Anti-Mullerian hormone (AMH) production through sertoli cell proliferation and a nonclassical cyclic adenosine 5'-monophosphate-mediated activation of the AMH Gene. Mol Endocrinol 2003; 17: 550-561.

18. Bergada I, Milani C, Bedecarras P, Andreone L, Ropelato MG, Gottlieb S, et al. Time course of the serum gonadotropin surge, inhibins, and anti-Mullerian hormone in normal newborn males during the first month of life. J Clin Endocrinol Metab 2006; 91: 4092-4098.

19. Forest MG, Sizonenko PC, Cathiard AM, Bertrand J. Hypophyso-gonadal function in humans during the first year of life. 1. Evidence for testicular activity in early infancy. J Clin Invest 1974; 53: 819-828.

20. Grinspon RP, Loreti N, Braslavsky D, Bedecarras P, Ambao V, Gottlieb S, et al. Sertoli cell markers in the diagnosis of paediatric male hypogonadism. J Pediatr Endocrinol Metab 2012; 25: 3-11.

21. Aksglaede $L$, Sorensen $K$, Boas $M$, Mouritsen $A$, Hagen CP, Jensen RB, et al. Changes in anti-Mullerian hormone (AMH) throughout the life span: a population-based study of 1027 healthy males from birth (cord blood) to the age of 69 years. J Clin Endocrinol Metab 2010; 95: 5357-5364.

22. Bergada I, Rojas G, Ropelato G, Ayuso S, Bergada C, Campo S. Sexual dimorphism in circulating monomeric and dimeric inhibins in normal boys and girls from birth to puberty. Clin Endocrinol (Oxf) 1999; 51: 455-460.

23. Young J, Chanson P, Salenave S, Noel M, Brailly S, O'Flaherty $\mathbf{M}$, et al. Testicular anti-mullerian hormone secretion is stimulated by recombinant human FSH in patients with congenital hypogonadotropic hypogonadism. J Clin Endocrinol Metab 2005; 90: 724-728.

24. Nistal M, Abaurrea MA, Paniagua R. Morphological and 
histometric study on the human Sertoli cell from birth to the onset of puberty. J Anat 1982; 134: 351-363.

25. Cassorla FG, Golden SM, Johnsonbaugh RE, Heroman WM, Loriaux DL, Sherins RJ. Testicular volume during early infancy. J Pediatr 1981; 99: 742-743.

26. Joustra SD, van der Plas EM, Goede J, Oostdijk W, Delemarre-van de Waal HA, Hack WW, et al. New reference charts for testicular volume in Dutch children and adolescents allow the calculation of standard deviation scores. Acta Paediatr 2015; 104: e271-278.

27. Sharpe RM, McKinnell C, Kivlin C, Fisher JS. Proliferation and functional maturation of Sertoli cells, and their relevance to disorders of testis function in adulthood. Reproduction 2003; 125: 769-784.

28. Rey R, Lordereau-Richard I, Carel JC, Barbet P, Cate RL, Roger M, et al. Anti-müllerian hormone and testosterone serum levels are inversely during normal and precocious pubertal development. J Clin Endocr Metab 1993; 77: $1220-1226$.

29. Rey R. Endocrine, paracrine and cellular regulation of postnatal anti-mullerian hormone secretion by sertoli cells. Trends Endocrinol Metab 1998; 9: 271-276.

30. Josso N, Rey R, Picard JY. Testicular anti-Mullerian hor mone: clinical applications in DSD. Semin Reprod Med 2012; 30: 364-373.

31. De Santa Barbara P, Bonneaud N, Boizet B, Desclozeaux M, Moniot B, Sudbeck P, et al. Direct interaction of SRY-related protein SOX9 and steroidogenic factor 1 regulates transcription of the human anti-Mullerian hormone gene. Mol Cell Biol 1998; 18: 6653-6665.

32. Viger RS, Mertineit C, Trasler JM, Nemer M. Transcrip tion factor GATA-4 is expressed in a sexually dimorphic pattern during mouse gonadal development and is a potent activator of the Mullerian inhibiting substance promoter. Development 1998; 125: 2665-2675.

33. Hossain A, Saunders GF. Role of Wilms Tumor 1 (WT1) in the Transcriptional Regulation of the Mullerian-Inhibiting Substance Promoter1. Biol Reprod 2003; 69: 1808-1814.

34. Lee MM, Donahoe PK, Hasegawa T, Silverman B, Crist GB, Best S, et al. Mullerian inhibiting substance in humans: normal levels from infancy to adulthood. J Clin Endocrinol Metab 1996; 81: 571-576.

35. Rey R, Lukas-Croisier C, Lasala C, Bedecarras P. AMH/ MIS: what we know already about the gene, the protein and its regulation. Mol Cell Endocrinol 2003; 211: 21-31.

36. Grinspon RP, Rey RA. Anti-mullerian hormone and sertoli cell function in paediatric male hypogonadism. Horm Res Paediatr 2010; 73: 81-92.

37. Chemes HE, Rey RA, Nistal M, Regadera J, Musse M, Gonzalez-Peramato P, et al. Physiological androgen insensitivity of the fetal, neonatal, and early infantile testis is explained by the ontogeny of the androgen receptor expression in Sertoli cells. J Clin Endocrinol Metab 2008; 93: 4408-4412.

38. Boukari K, Meduri G, Brailly-Tabard S, Guibourdenche J, Ciampi ML, Massin N, et al. Lack of androgen receptor expression in Sertoli cells accounts for the absence of anti-Mullerian hormone repression during early human testis development. J Clin Endocrinol Metab 2009; 94 1818-1825.

39. Berensztein EB, Baquedano MS, Gonzalez CR, Saraco NI, Rodriguez J, Ponzio R, et al. Expression of aromatase, es- trogen receptor alpha and beta, androgen receptor, and cytochrome $\mathrm{P}-450 \mathrm{scc}$ in the human early prepuberta testis. Pediatr Res 2006; 60: 740-744.

40. Omabe M, Ezeani M, Martin O. Clinical Utilities of Ant Mullerian Hormone. Sch J App Med Sci 2013; Vol 1: 606618.

41. Jamil Z, Fatima SS, Ahmed K, Malik R. Anti-Mullerian Hormone: Above and Beyond Conventional Ovarian Reserve Markers. Dis Markers 2016; 2016: 5246217.

42. Wherrett DK. Approach to the Infant with a Suspected Disorder of Sex Development. Pediatr Clin North Am 2015; 62: 983-999.

43. Ahmed SF, Achermann JC, Arlt W, Balen A, Conway G, Edwards Z, et al. Society for Endocrinology UK guidance on the initial evaluation of an infant or an adolescent with a suspected disorder of sex development (Revised 2015). Clin Endocrinol (Oxf) 2016; 84: 771-788.

44. Ostrer H. Disorders of sex development (DSDs): an update. J Clin Endocrinol Metab 2014; 99: 1503-1509.

45. Lee MM, Misra M, Donahoe PK, MacLaughlin DT. MIS/ $\mathrm{AMH}$ in the assessment of cryptorchidism and intersex conditions. Mol Cell Endocrinol 2003; 211: 91-98.

46. Rey RA, Codner E, Iniguez G, Bedecarras P, Trigo R, Okuma $\mathbf{C}$, et al. Low risk of impaired testicular Sertoli and Leydig cell functions in boys with isolated hypospadias. J Clin Endocrinol Metab 2005; 90: 6035-6040.

47. Abduljabbar M, Taheini K, Picard JY, Cate RL, Josso N. Mutations of the AMH type II receptor in two extended families with persistent Mullerian duct syndrome: lack of phenotype/genotype correlation. Horm Res Paediatr 2012; 77: 291-297.

48. Josso N, Belville C, di Clemente N, Picard JY. AMH and $\mathrm{AMH}$ receptor defects in persistent Mullerian duct syndrome. Hum Reprod Update 2005; 11: 351-356.

49. Lang-Muritano M, Biason-Lauber A, Gitzelmann C, Belville C, Picard Y, Schoenle EJ. A novel mutation in the anti-mullerian hormone gene as cause of persistent mullerian duct syndrome. Eur J Pediatr 2001; 160: 652-654.

50. Rey R. Anti-müllerian hormone in disorders of sex determination and differentiation. Arq Bras Endocrinol Metabol 2005; 49: 26-36

51. Grinspon RP, Nevado J, Mori Alvarez Mde L, Del Rey G, Castera R, Venara M, et al. 46,XX ovotesticular DSD associated with a SOX3 gene duplication in a SRY-negative boy. Clin Endocrinol (Oxf) 2016; 85: 673-675

52. Rey RA, Belville C, Nihoul-Fekete C, Michel-Calemard L, Forest MG, Lahlou N, et al. Evaluation of gonadal function in 107 intersex patients by means of serum antimullerian hormone measurement. J Clin Endocrinol Metab 1999; 84: 627-631.

53. Kumar P, Kumar N, Thakur DS, Patidar A. Male hypogonadism: Symptoms and treatment. J Adv Pharm Technol Res 2010; 1: 297-301.

54. Bonomi M, Libri DV, Guizzardi F, Guarducci E, Maiolo E, Pignatti E, et al. New understandings of the genetic basis of isolated idiopathic central hypogonadism. Asian J Androl 2012; 14: 49-56.

55. Viswanathan V, Eugster EA. Etiology and Treatment of Hypogonadism in Adolescents. Pediatr Clin North Am 2011; 58: 1181-1200.

56. Surampudi $\mathbf{P}$, Swerdloff RS, Wang $\mathbf{C}$. An update on male hypogonadism therapy. Expert Opin Pharmacother 2014; 
15: $1247-1264$.

57. Adan L, Lechevalier P, Couto-Silva AC, Boissan M, Trivin C, Brailly-Tabard S, et al. Plasma inhibin B and antimullerian hormone concentrations in boys: discriminating between congenital hypogonadotropic hypogonadism and constitutional pubertal delay. Med Sci Monit 2010; 16: CR511-517.

58. Coutant R, Biette-Demeneix E, Bouvattier C, Bouhours-Nouet N, Gatelais F, Dufresne S, et al. Baseline inhibin $B$ and anti-Mullerian hormone measurements for diagnosis of hypogonadotropic hypogonadism $(\mathrm{HH})$ in boys with delayed puberty. J Clin Endocrinol Metab 2010; 95: 5225-5232.

59. Young J, Rey R, Couzinet B, Chanson P, Josso N, Schaison G. Antimullerian hormone in patients with hypogonadotropic hypogonadism. J Clin Endocrinol Metab 1999; 84: 2696-2699.

60. Nieschlag E. Klinefelter syndrome: the commonest form of hypogonadism, but often overlooked or untreated. Dtsch Arztebl Int 2013; 110: 347-353.

61. Groth KA, Skakkebaek A, Host C, Gravholt CH, Bojesen A. Clinical review: Klinefelter syndrome--a clinical update. J Clin Endocrinol Metab 2013; 98: 20-30.

62. Lanfranco F, Kamischke A, Zitzmann M, Nieschlag E. Klinefelter's syndrome. Lancet 2004; 364: 273-283.

63. Bastida MG, Rey RA, Bergada I, Bedecarras P, Andreone L, del Rey G, et al. Establishment of testicular endocrine function impairment during childhood and puberty in boys with Klinefelter syndrome. Clin Endocrinol (Oxf) 2007; 67: 863-870.

64. Lahlou N, Fennoy I, Carel JC, Roger M. Inhibin B and anti-Mullerian hormone, but not testosterone levels, are normal in infants with nonmosaic Klinefelter syndrome. J Clin Endocrinol Metab 2004; 89: 1864-1868.

65. Aksglaede L, Christiansen P, Sorensen K, Boas M, Linneberg A, Main KM, et al. Serum concentrations of Anti-Mullerian Hormone (AMH) in 95 patients with Klinefelter syndrome with or without cryptorchidism. Acta Paediatr 2011; 100: 839-845.

66. Pacenza N, Pasqualini T, Gottlieb S, Knoblovits P, Costanzo PR, Stewart Usher J, et al. Clinical Presentation of Klinefelter's Syndrome: Differences According to Age. Int J Endocrinol 2012; 2012: 324835

67. Radmayr C, Dogan HS, Hoebeke P, Kocvara R, Nijman $\mathbf{R}$, Stein R, et al. Management of undescended testes: European Association of Urology/European Society for Paediatric Urology Guidelines. J Pediatr Urol 2016; 12: 335-343.

68. Niedzielski JK, Oszukowska E, Słowikowska-Hilczer J. Undescended testis - current trends and guidelines: a review of the literature. Arch Med Sci 2016; 12: 667-677.

69. Penson D, Krishnaswami S, Jules A, McPheeters ML. Effectiveness of hormonal and surgical therapies for cryptorchidism: a systematic review. Pediatrics 2013; 131: e1897-1907.

70. Blanco S, Gottlieb S, Grinspon R, Rey R. Criptorquidia: desde la embriología al tratamiento. Revista Médicas UIS 2015; 28: 371-380.

71. Cortes D, Thorup JM, Visfeldt J. Cryptorchidism: aspects of fertility and neoplasms. A study including data of 1,335 consecutive boys who underwent testicular biopsy simultaneously with surgery for cryptorchidism. Horm
Res 2001; 55: 21-27.

72. Cortes D, Clasen-Linde E, Hutson JM, Li R, Thorup J. The Sertoli cell hormones inhibin-B and anti Mullerian hormone have different patterns of secretion in prepubertal cryptorchid boys. J Pediatr Surg 2016; 51: 475-480.

73. Grinspon RP, Ropelato MG, Bedecarras P, Loreti N, Ballerini MG, Gottlieb S, et al. Gonadotrophin secretion pattern in anorchid boys from birth to pubertal age: pathophysiological aspects and diagnostic usefulness. Clin Endocrinol (Oxf) 2012; 76: 698-705.

74. Elder JS. Ultrasonography is unnecessary in evaluating boys with a nonpalpable testis. Pediatrics 2002; 110: 748-751.

75. Hrebinko RL, Bellinger MF. The limited role of imaging techniques in managing children with undescended testes. J Urol 1993; 150: 458-460.

76. Lee MM, Donahoe PK, Silverman BL, Hasegawa T, Hasegawa Y, Gustafson ML, et al. Measurements of serum mullerian inhibiting substance in the evaluation of children with nonpalpable gonads. N Engl J Med 1997; 336: 1480-1486.

77. Misra M, MacLaughlin DT, Donahoe PK, Lee MM. Measurement of Mullerian inhibiting substance facilitates management of boys with microphallus and cryptorchidism. J Clin Endocrinol Metab 2002; 87: 3598-3602.

78. Rey RA, Venara M, Coutant R, Trabut J-B, Rouleau S, Lahlou N, et al. Unexpected mosaicism of R201H-GNAS1 mutant-bearing cells in the testes underlie macro-orchidism without sexual precocity in McCune-Albright syndrome. Hum Mol Genet 2006; 15: 3538-3543.

79. Carel JC, Leger J. Clinical practice. Precocious puberty. N Engl J Med 2008; 358: 2366-2377.

80. Fuqua JS. Treatment and outcomes of precocious puberty: an update. J Clin Endocrinol Metab 2013; 98: 21982207.

81. Brito VN, Spinola-Castro AM, Kochi C, Kopacek C, Silva PCAd, Guerra-Júnior G. Central precocious puberty: revisiting the diagnosis and therapeutic management. Arch Endocrinol Metab 2016; 60: 163-172.

82. Grinspon RP, Andreone L, Bedecarrás P, Ropelato MG, Rey RA, Campo SM, et al. Male Central Precocious Puberty: Serum Profile of Anti-müllerian Hormone and Inhibin B before, during, and after Treatment with $\mathrm{GnRH}$ Analogue. Int J Endocrinol 2013; 2013: 823064.

83. Abitbol L, Zborovski S, Palmert MR. Evaluation of delayed puberty: what diagnostic tests should be performed in the seemingly otherwise well adolescent? Arch Dis Child 2016; 101: 767-771.

84. Wei C, Crowne EC. Recent advances in the understanding and management of delayed puberty. Arch Dis Child 2016; 101: 481-488.

85. Palmert MR, Dunkel L. Clinical practice. Delayed puberty. N Engl J Med 2012; 366: 443-453.

86. Rohayem J, Nieschlag E, Kliesch S, Zitzmann M. Inhibin $\mathrm{B}, \mathrm{AMH}$, but not INSL3, IGF1 or DHEAS support differentiation between constitutional delay of growth and puberty and hypogonadotropic hypogonadism. Andrology 2015; 3: 882-887.

87. Rey R, Sabourin JC, Venara M, Long WQ, Jaubert F, Zeller WP, et al. Anti-Mullerian hormone is a specific marker of sertoli- and granulosa-cell origin in gonadal tumors. Hum Pathol 2000; 31: 1202-1208. 
88. Venara M, Rey R, Bergada I, Mendilaharzu H, Campo S, Chemes H. Sertoli cell proliferations of the infantile testis: an intratubular form of Sertoli cell tumor? Am J Surg Pathol 2001; 25: 1237-1244.

89. Chemaitilly W, Cohen LE. DIAGNOSIS OF ENDOCRINE DISEASE: Endocrine late-effects of childhood cancer and its treatments. Eur J Endocrinol 2017; 176: R183-R203.

90. Patterson BC, Wasilewski-Masker K, Ryerson AB, Mertens A, Meacham L. Endocrine health problems detected in 519 patients evaluated in a pediatric cancer survivor program. J Clin Endocrinol Metab 2012; 97: 810-818.

91. Levi M, Hasky N, Stemmer SM, Shalgi R, Ben-Aharon I. Anti-Mullerian Hormone Is a Marker for Chemotherapy-Induced Testicular Toxicity. Endocrinology 2015; 156: 3818-3827.

92. Cuny A, Trivin C, Brailly-Tabard S, Adan L, Zerah M, Sainte-Rose $\mathrm{C}$, et al. Inhibin B and anti-Mullerian hormone as markers of gonadal function after treatment for medulloblastoma or posterior fossa ependymoma during childhood. J Pediatr 2011; 158: 1016-1022 e1011.

93. Baker ML, Metcalfe SA, Hutson JM. Serum levels of mullerian inhibiting substance in boys from birth to 18 years, as determined by enzyme immunoassay. J Clin Endocrinol Metab 1990; 70: 11-15.

94. Hudson PL, Dougas I, Donahoe PK, Cate RL, Epstein J, Pepinsky RB, et al. An immunoassay to detect human mullerian inhibiting substance in males and females during normal development. J Clin Endocrinol Metab 1990; 70: 16-22.

95. Josso N, Legeai L, Forest MG, Chaussain JL, Brauner R An enzyme linked immunoassay for anti-mullerian hormone: a new tool for the evaluation of testicular function in infants and children. J Clin Endocrinol Metab 1990; 70:
23-27.

96. Al-Qahtani A, Muttukrishna S, Appasamy M, Johns J, Cranfield M, Visser JA, et al. Development of a sensitive enzyme immunoassay for anti-Mullerian hormone and the evaluation of potential clinical applications in males and females. Clin Endocrinol (Oxf) 2005; 63: 267-273.

97. Freour T, Mirallie S, Bach-Ngohou K, Denis M, Barriere $P$, Masson D. Measurement of serum anti-Mullerian hormone by Beckman Coulter ELISA and DSL ELISA: comparison and relevance in assisted reproduction technology (ART). Clin Chim Acta 2007; 375: 162-164.

98. Kumar A, Kalra B, Patel A, McDavid L, Roudebush WE. Development of a second generation anti-Mullerian hormone (AMH) ELISA. J Immunol Methods 2010; 362: 5159.

99. Nelson SM, La Marca A. The journey from the old to the new AMH assay: how to avoid getting lost in the values. Reprod Biomed Online 2011; 23: 411-420.

100. Li HW, Wong BP, Ip WK, Yeung WS, Ho PC, Ng EH. Comparative evaluation of three new commercial immunoassays for anti-Mullerian hormone measurement. Hum Reprod 2016; 31: 2796-2802.

101. Ansh Labs LLC. Ultra-Sensitive AMH/MIS ELISA. 2014. Disponible: https://www.anshlabs.com/wp-content/ uploads/inserts/AL105.pdf. Consultado: jun 2017.

102. Roche Diagnostics International Ltd. Elecsys ${ }^{\circledast} \mathrm{AMH}$

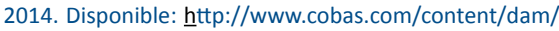
cobas_com/pdf/product/Elecsys $\% 20 \mathrm{AMH} /$ Elecsys $\% 20$ AMH\%20FactSheet.pdf. Consultado: jun 2017.

103. Welsh P, Smith K, Nelson SM. A single-centre evaluation of two new anti-Mullerian hormone assays and comparison with the current clinical standard assay. Hum Reprod 2014; 29: 1035-1041.

\begin{abstract}
The antimullerian hormone, initially referred as mullerian inhibitory substance, is a $12.5 \mathrm{kDa}$ homodimeric glycoprotein, belonging to the transforming growth factor beta (TGF-6) family that playing a crucial role in male sexual differentiation by favoring regression of the Mullerian ducts. Since their production in the male is mainly by the immature Sertoli cells, in the last decades its usefulness has growth beyond the evaluation of the ovarian function and female fertility treatments, which has allowed evaluating the testicular function in male and affections such as hypogonadism, disorders of sexual differentiation, pathological puberty, cryptorchidism and others clinical conditions reviewed in this manuscript. In addition, this review describes the physiological role of the antimüllerian hormone in the prepubertal testes and the laboratory tests available for its measurement.
\end{abstract}

Key words: anti-mullerian hormone, male, Sertoli cells, sex differentiation, 46, XX testicular disorders of sex development, hypogonadism, cryptorchidism, Klinefelter syndrom. 